\title{
Major clinical research advances in gynecologic cancer in 2012
}

\author{
Dong Hoon Suh ${ }^{1}$, Jae-Weon Kim ${ }^{1}$, Kidong Kim ${ }^{2}$, Hak Jae Kim³ ${ }^{3}$ Kyung-Hun Lee ${ }^{4}$ \\ ${ }^{1}$ Department of Obstetrics and Gynecology, Seoul National University College of Medicine, Seoul; ${ }^{2}$ Department of Obstetrics \\ and Gynecology, Seoul National University Bundang Hospital, Seongnam; ' ${ }^{2}$ epartment of Radiation Oncology, Seoul National \\ University College of Medicine, Seoul; ${ }^{4}$ Department of Internal Medicine, Seoul National University Hospital, Seoul, Korea
}

Ten topics were chosen among major clinical research achievements in gynecologic oncology in 2012. For ovarian cancer, comprehensive review of the history of bevacizumab studies was followed by poly adenosine diphosphate [ADP]-ribose polymerase (PARP) inhibitors and other molecular targeted agents such as epidermal growth factor receptor tyrosine kinase inhibitor and AMG 386. For the development of genomic study in gynecologic cancers, BRCA and DICER1 mutations were covered in epithelial and nonepithelial ovarian cancer, respectively. For endometrial cancer, targeted agents including mammalian target of rapamycin (mTOR) inhibitors and bevacizumab were discussed. Radiation therapy "sandwiched" between combination chemotherapy schedules for the treatment of uterine papillary serous carcinoma was also reviewed. Preoperative prediction of lymph node metastasis, definition of low-risk group, and recurrence and survival outcomes of laparoscopic approaches were addressed. For cervical cancer, we reviewed long-term benefit of human papillomavirus test and efficacy of paclitaxel/carboplatin versus paclitaxel/cisplatin in stage IVB, persistent or recurrent disease. In addition, the effect of three dimensional image-based high-dose rate brachytherapy was also reviewed. For vulvar cancer, the diagnostic value of sentinel lymph node biopsy was discussed. For breast cancer, positive results of three outstanding phase III randomized clinical trials, CLEOPATRA, EMILIA, and BOLERO-2 were introduced. Lastly, updates of major practice guidelines were summarized.

Keywords: Bevacizumab, PARP inhibitor, Low-risk endometrial cancer, Image-based high-dose rate brachytherapy, Practice guidelines

\section{INTRODUCTION}

Although there was no groundbreaking and innovative discovery in gynecologic oncology clinical researches, several influential reports from big trials were released in 2012. Increasing number of molecular targeted agents including anti-angiogenic agents and poly (adenosine diphosphate [ADP]-ribose) polymerase (PARP) inhibitors newly entered into clinical trials or was under investigation in clinical trials for ovarian cancer in various first-line or salvage treatment

Received Dec 31, 2012, Accepted Jan 2, 2013

Correspondence to Jae-Weon Kim

Department of Obstetrics and Gynecology, Seoul National University College of Medicine, 101 Daehak-ro, Jongno-gu, Seoul 110-744, Korea. Tel: +82-2-2072-3511, Fax: +82-2-762-3599, E-mail: kjwksh@snu.ac.kr settings. Long debate on the roles of lymphadenectomy (LND) and definition of low-risk group in endometrial cancer is still under fire. We hereby sum up the results of recently published studies and current status of the relevant trials. In addition, we decided to cover in this review the updates of major practice guidelines in gynecologic oncology, hoping to be of help to both clinicians and researchers in their daily routines.

\section{UNFINISHED STORY OF BEVACIZUMAB IN OVARIAN CANCER}

Final reports of two studies of bevacizumab as front-line therapy in ovarian cancer, Gynecologic Oncology Group (GOG) 218 and ICON 7, were released at by the end of $2011[1,2]$. To conclude GOG 218, Burger et al. [1] indicated that the use of bevacizumab up to 10 months after paclitaxel and carboplatin

Copyright ( 2013. Asian Society of Gynecologic Oncology, Korean Society of Gynecologic Oncology 
(TC) prolonged the median progression-free survival (PFS) by about 4 months in patients with advanced epithelial ovarian cancer (EOC). Similarly Perren et al. [2] reported in International Collaborative Ovarian Neoplasm (ICON) 7 significant improvement of PFS by about 2 months in bevacizumab-added group compared with TC group with a maximum effect at 12 months, coinciding with the end of planned bevacizumab treatment and diminishing by 24 months. They also reported that PFS and overall survival (OS) of TC group were greater among those at high risk for disease progression.

As for platinum-sensitive recurrent disease, the results of the OCEANS trial were finally updated and published in 2012 [3]. Addition of bevacizumab to gemcitabine and carboplatin (GC) followed by bevacizumab until progression was shown to significantly improve PFS compared with GC plus placebo in platinum-sensitive recurrent ovarian cancer. Although no safety concerns were newly noted, more frequent grade 3 or higher hypertension and proteinuria were reported in the bevacizumab group. Fortunately, an updated safety analysis of OCEANS, which was released 11 months after the data cutoff date for the final PFS analysis and was presented at 2012 American Society of Clinical Oncology (ASCO) annual meeting, seemed to ease the concerns over long-term severe adverse events of bevacizumab [4]. More patients in the bevacizumab group (20.6\%) than in the placebo group (4.7\%) experienced an adverse event that led to discontinuation of study drug, in the bevacizumab group most commonly due to hypertension $(4 \%)$, proteinuria (2.8\%), epistaxis (1.2\%), and thrombocytopenia (1.6\%). In patients with grade $\geq 3$ hypertension and proteinuria, median numbers of bevacizumab cycles were 16.5 and 22.5 , and the adverse event resolved in $72.7 \%$ and $91.7 \%$, respectively. They concluded that no new safety signals were observed, and hypertension and proteinuria resolved upon discontinuation of bevacizumab in the majority of patients.

Regarding platinum-resistant recurrent disease, the preliminary result of AURELIA study was presented at 2012 ASCO annual meeting [5]. A total of 361 patients were randomized to receive selected chemotherapy alone (pegylated liposomal doxorubicin [PLD], 126; weekly paclitaxel [WPAC], 115; topotecan, 120) or with bevacizumab. At median follow-up of 13.5 months, there were 301 PFS events, 166 (91\%) vs. 135 (75\%) in chemotherapy alone and bevacizumab added group, respectively (hazard ratio [HR], 0.48; 95\% confidence interval [Cl], 0.38 to $0.60 ; p<0.001$ ). Objective response rates (ORR) were $12.6 \%$ and $30.9 \%$ in chemotherapy alone and bevacizumab added group, respectively $(p=0.001)$. Thus, in AURELIA, as the first phase III trial in platinum-resistant recurrent ovarian cancer to show benefit with a targeted therapy, chemotherapy combined with bevacizumab provided significant improvement in
PFS and ORR compared with chemotherapy alone. In addition, the results from a sub-group analysis of patients of AURELIA study with demonstrable ascites were reported in the 2012 International Gynecologic Cancer Society (IGCS) meeting in Vancouver [6]. Dr. Kristensen presented that among 113 patients with ascites, 54 in chemotherapy alone and 59 in bevacizumab added group, 10/54 (19\%) vs. 1/59 (2\%) underwent paracentesis during study treatment, respectively. Improved control of ascites was determined by the absence of paracentesis after the first dose of bevacizumab. Thus, the clinical value of the addition of bevacizumab to chemotherapy was also demonstrated in terms of ascites control.

Based on the promising results of GOG 218 and ICON 7 as well as the Japanese Gynecologic Oncologic Group (JGOG) study with dose-dense WPAC plus carboplatin [7], the singlearm OCTAVIA study evaluated front-line bevacizumab combined with WPAC and q 3 wks carboplatin for ovarian cancer and the final safety results were presented at 2012 ASCO annual meeting [8]. A total of 189 patients received 6-8 cycles of bevacizumab $\left(7.5 \mathrm{mg} / \mathrm{kg}\right.$, D1) plus WPAC $\left(80 \mathrm{mg} / \mathrm{m}^{2}, \mathrm{D} 1,8\right.$, 15) plus $C(A \cup C 6, D 1)$ intravenous $q 3$ wks, with bevacizumab q 3 wks continued alone for up to 17 cycles (1 year) as frontline therapy for newly diagnosed ovarian cancer. Patients received a median of 6 chemotherapy cycles (range, 1 to 8 ) and 17 bevacizumab (range, 0 to 18). Of the 168 patients who received single-agent bevacizumab, 135 (80\%) completed 1 year of therapy. Twelve percent of the patients discontinued bevacizumab for adverse events such as hypertension (4.2\%), thromboembolic events (6.3\%), bleeding (0.5\%), grade 3 wound-healing complications $0.5 \%$, and grade 4 gastrointestinal perforation (0.5\%). Bevacizumab combined with wPAC, therefore, could be a feasible and well-tolerated regimen for ovarian cancer.

At 2012 ASCO annual meeting, Roche set forth Grand Plan for "non-stop bevacizumab treatment" through presenting promising results of TML study [9]. In TML study, 820 patients with unresectable, metastatic colorectal cancer who progressed within 3 months after discontinuation of first-line bevacizumab plus chemotherapy were randomized to secondline fluoropyrimidine-based chemotherapy \pm bevacizumab. TML study is the first study demonstrating that bevacizumab plus chemotherapy (crossed over from first-line regimen) continued beyond progression significantly prolonged OS and PFS in second-line setting of metastatic colorectal cancer, proving that duration of treatment matters, i.e., "You start and don't stop." By contrast, a multicenter retrospective analysis of patients with EOC who progressed on bevacizumab therapy showed that PFS was statistically higher in no-bevacizumab beyond progression (BBP) group than that of BBP groups [10]. 
Moreover, patients who received bevacizumab first-line had a PFS of 11 months versus 5 months when initiated at first recurrence $(p=0.01)$. Nevertheless, considering that the limited efficacy of the continued use of BBP in EOC was the result of a retrospective study with a small number of patients, Roche sees ovarian cancer as a growth driver for bevacizumab. A convergence of the PFS curves was observed in GOG 218 and ICON 7, but not in OCEANS trial in which bevacizumab was continued until disease progression. It was suggested that the magnitude of benefit of bevacizumab might correlate directly with treatment duration that angiogenesis is a hostrelated process that could be inhibited but not eradicated [1]. Confirmation that this hypothesis holds true for ovarian cancer is warranted in the future.

\section{PARP INHIBITORS IN OVARIAN CANCER}

PARP plays an important role in the repair of single-stranded DNA breaks, through the base excision repair pathway, keeping low-fidelity nonhomologous-end-joining DNA repair machinery in check [11]. Patients with EOC who harbor germline mutations in BRCA1/2 genes, approximately $10 \%$ of cases of EOC, exhibit defects in homologous recombination DNA repair [12]. However, The Cancer Genome Atlas (TCGA) analysis of serous EOC documented that approximately $50 \%$ of serous EOC cases might have disruption of the homologous recombination pathway and be susceptible to PARP inhibitors [13].

Olaparib, a potent oral PARP inhibitor, induces synthetic lethality in BRCA-deficient tumor cells [14]. Recently, Kaye et al. [15] reported the results of a phase II study in patients with recurrent ovarian cancer with germ-line BRCA mutations, in which the efficacy and safety of olaparib were compared with those of PLD. A total of 97 patients with platinum-resistant recurrent ovarian cancer were randomly assigned in a 1:1:1 ratio to olaparib $200 \mathrm{mg}$ bid or $400 \mathrm{mg}$ bid continuously or PLD $50 \mathrm{mg} / \mathrm{m}^{2}$ intravenously q $4 \mathrm{wks}$. Median PFS was 6.5 ( $95 \% \mathrm{Cl}, 5.5$ to 10.1), 8.8 ( $95 \% \mathrm{Cl}, 5.4$ to 9.2), and 7.1 months ( $95 \% \mathrm{Cl}, 3.7$ to 10.7) for the olaparib $200 \mathrm{mg}$, olaparib $400 \mathrm{mg}$, and PLD groups, respectively. No significant difference was seen in the primary endpoint of PFS between the olaparib and PLD groups ( $\mathrm{HR}, 0.88 ; 95 \% \mathrm{Cl}, 0.51$ to $1.56 ; \mathrm{p}=0.66$ ). It was suggested that this insignificant difference might simply be the result of random variation, considering that the median PFS of 5.8 months in previous trial by Audeh et al. [16] was within the $95 \% \mathrm{Cl}$ (5.4 to 9.2 months) [12]. Konstantinopoulos et al. [12] also suggested three other plausible reasons for the negative results of this study by Kaye et al. [15]. First, relatively high proportion of platinum-sensitive patients (57.6\%) in the PLD group compared with olaparib groups (46.9\% and $43.8 \%$ in $400 \mathrm{mg}$ and $200 \mathrm{mg}$ groups, respectively) might have led to an underestimation of olaparib benefit, given the lower responsiveness of olaparib and PLD in platinumsensitive patients than platinum-resistant patients (33.5\% vs. $46.2 \%$ for olaparib [17] and $12.3 \%$ vs. $28.4 \%$ for PLD [18], respectively). Second, the predominance of BRCA1 mutation over BRCA2 mutation in each group could be one of the possible explanations for unsatisfactory activity of olaparib, considering known higher chemo-sensitivity of EOC patients with BRCA2 mutations than with BRCA1 mutations [19]. Lastly, higher proportion of more heavily pretreated patients in the olaparib $400 \mathrm{mg}$ group than PLD group (78.2\% vs. 51.5\%) may contribute to the development of secondary somatic mutations that restore BRCA1/2 function and may confer resistance to olaparib [20].

The antitumor activity of olaparib was also demonstrated in patients with platinum-sensitive recurrent high-grade serous ovarian cancer (HGS-OC) irrespective of BRCA1/2 germ-line mutations status, the interim analysis results of which were published in 2012 [21]. Two hundred sixty-five patients were randomized to the olaparib group (136 patients) and the placebo group (129 patients). Median PFS was significantly longer with olaparib than with placebo (8.4 vs. 4.8 months; $\mathrm{HR}, 0.35 ; 95 \% \mathrm{Cl}, 0.25$ to $0.49 ; \mathrm{p}<0.001)$. However, there was no significant difference of OS between groups at the time of interim analysis ( $\mathrm{HR}, 0.94 ; 95 \% \mathrm{Cl}, 0.63$ to $1.39 ; \mathrm{p}=0.75$ ). Thus, they concluded that olaparib maintenance therapy significantly improved PFS in patients with platinum-sensitive, recurrent, HGS-OC with tolerable toxicity profiles.

\section{THE BEST POSSIBLE TREATMENT REGIMENS IN OVARIAN CANCER}

Various attempts to find out drugs for better survival outcomes in ovarian cancer can be largely divided into two ways: 1) molecular targeted agents with or without chemotherapy and 2) modification of dose and schedule or different combinations of chemotherapeutic agents.

There are enormous numbers of molecular targeted agents which are under development. Among those, only a few shows promising results in clinical trials. Vergote et al. [22] presented the results of phase III study of erlotinib, an epidermal growth factor receptor (EGFR) tyrosine kinase inhibitor, versus observation in patients with no evidence of disease progression after first-line platinum-based chemotherapy for ovarian carcinoma at 2012 ASCO annual meeting. The eligible 835 patients were randomized to maintenance erlotinib 150 
$\mathrm{mg} /$ day for 2 years $(\mathrm{n}=420)$ or observation $(n=415)$. At median follow-up period of 51 months, median PFS was 12.7 and 12.4 months for erlotinib and observation group, respectively (HR, $1.05 ; 95 \% \mathrm{Cl}, 0.90$ to $1.23 ; \mathrm{p}=0.525)$. Median OS was 50.8 and 59.1 months for erlotinib and observation group, respectively ( $H R, 0.99 ; 95 \% \mathrm{Cl}, 0.81$ to $1.20 ; \mathrm{p}=0.903$ ). Twenty-five percent of the patients stopped erlotinib due to side effects, most commonly diarrhea and rash. They concluded that maintenance erlotinib after first-line treatment in ovarian cancer did not improve PFS or OS.

Another negative trial published in 2012 is a phase III study comparing the efficacy and safety of patupilone, a novel microtubule-stabilizing agent, with those of PLD in patients with platinum-refractory or -resistant epithelial ovarian, primary fallopian tube, or primary peritoneal cancer [23]. Based on antiproliferative activity in paclitaxel-resistant ovarian cancer cell lines and in cells with a multidrug-resistant phenotype [24,25], clinical trials of early phases have demonstrated comparable disease control rate and manageable toxicities of patupilone in platinum-refractory or -resistant settings [26]. However, patupilone did not demonstrate significant improvement in OS compared with PLD in this phase III study by Colombo et al. [23] in which a total of 829 patients were randomly assigned to patupilone $\left(n=412,10 \mathrm{mg} / \mathrm{m}^{2}\right.$ intravenously q 3 wks) or PLD ( $n=417,50 \mathrm{mg} / \mathrm{m}^{2}$ intravenously q 4 wks) group. Median OSs were 13.2 and 12.7 months with patupilone and PLD groups, respectively ( $\mathrm{HR}, 0.93 ; 95 \% \mathrm{Cl}, 0.79$ to 1.09 ; $\mathrm{p}=0.195$ ). Median PFS was 3.7 months for both groups.

AMG 386 is an investigational anti-angiogenic recombinant peptide-Fc fusion protein that neutralizes the interaction between the Tie2 receptor and angiopoietin 1 and 2. Although both angiopoietin and vascular endothelial growth factor (VEGF) are involved in pathologic angiogenesis in ovarian cancer [27], anti-angiogenic peptibody AMG 386 did not present serious adverse events such as bowel perforation, the risk of which might be increased by anti-VEGF antibody bevacizumab [28]. Based on the promising results of phase I clinical trials [29,30], a phase II study of AMG 386 combined with WPAC was conducted in patients with recurrent ovarian cancer [31]. A total of 161 patients were randomly assigned in a 1:1:1 ratio to receive paclitaxel $\left(80 \mathrm{mg} / \mathrm{m}^{2}\right.$ weekly, 3 weeks on/1 week off) plus weekly intravenous AMG $38610 \mathrm{mg} / \mathrm{kg}$ (arm A), AMG 3863 mg/kg (arm B), or placebo (arm C). Median PFS was $7.2(95 \% \mathrm{Cl}, 5.3$ to 8.1), $5.7(95 \% \mathrm{Cl}, 4.6$ to 8.0$)$, and 4.6 ( $95 \% \mathrm{Cl}, 1.9$ to 6.7$)$ months in arm A, B, and C, respectively. The $\mathrm{HR}$ for arms $\mathrm{A}$ and $\mathrm{B}$ combined vs. arm C was $0.76(95 \% \mathrm{Cl}, 0.52$ to 1.12; $p=0.165$ ). Objective response rates for arms $A, B$, and $C$ were $37 \%, 19 \%$, and $27 \%$, respectively. The incidence of grade 3 or higher adverse events in arm A, B, and C was $65 \%, 55 \%$, and $64 \%$, respectively, commonly hypertension $(8 \%, 6 \%$, and $5 \%)$, peripheral edema $(71 \%, 51 \%$, and $22 \%$ ) and hypokalemia $(215,15 \%$, and $5 \%)$. They concluded that AMG 386 combined with WPAC was tolerable, with a manageable and distinct toxicity profile. Now, weekly AMG 386 is being investigated in phase III studies in primary (TRINOVA-3; ClinicalTrials.gov, NCT01493505) and recurrent settings (TRINOVA-1; ClinicalTrials.gov, NCT01204749).

At the 2012 IGCS meeting in Vancouver, the phase III HECTOR study was presented [32]. Based on the promising results of phase I and II studies of topotecan and carboplatin in platinum-sensitive recurrent ovarian cancer [33,34], HECTOR study enrolled 550 patients and compared topotecan and carboplatin with three well-established platinum-based regimens, gemcitabine plus carboplatin, PLD plus carboplatin and TC in terms of the efficacy of the two arms. Regarding toxicity profile, less long-term or severe toxicity was observed in experimental arm than control arm. However, topotecan and carboplatin did not meet the primary endpoint of improving 1 year OS. Considering the HECTOR study was designed as superiority trial, thus, topotecan and carboplatin was found to be not superior to other established regimens.

Lastly, long-term follow-up results of JGOG 3016 trial (NOVEL study) were presented at 2012 ASCO annual meeting, which compared conventional TC (c-TC) with dose-dense weekly TC (dd-TC) in women with advanced epithelial ovarian, fallopian tube, or primary peritoneal cancer [35]. After the promising report of primary analysis [36], long-term follow-up results on PFS and OS were released in 3 years. A total of 631 patients were randomly assigned to receive c-TC (paclitaxel $180 \mathrm{mg} /$ $\mathrm{m}^{2}$ and carboplatin AUC 6 on D1) or dd-TC (paclitaxel $80 \mathrm{mg} /$ $\mathrm{m}^{2}$ on D1, 8, 15 and carboplatin AUC 6 on D1) for six cycles every 3 weeks. At 6.4 years of median follow-up, median PFS was 28.1 and 17.5 months for dd-TC and C-TC group, respectively ( $\mathrm{HR}, 0.75 ; 95 \% \mathrm{Cl}, 0.62$ to $0.91 ; \mathrm{p}=0.0037$ ). OS at 5 years was higher in the dd-TC group than c-TC group (58.6\% vs. $51.0 \% ; \mathrm{HR}, 0.79 ; 95 \% \mathrm{Cl}, 0.63$ to $0.99 ; \mathrm{p}=0.0448$ ). Thus, it was concluded that dd-TC improved long-term PFS and OS in patients with advanced EOC.

\section{GENOMICS OF GYNECOLOGIC CANCERS}

Since the integrated genomic analyses of HGS-OC by TCGA [37], a wide application of next generation DNA sequencing has brought challenging issues which were comprehensively discussed in European Society for Medical Oncology (ESMO) 2012 Congress in Vienna. Those who reap the greatest benefit from routine complete genome sequencing would be indi- 
viduals who inherited mutations conferring high cancer risks such as BRCA mutation carriers [38]. Given that approximately half of BRCA1/2 families do not have significant family history and homologous recombination defects might be present in about half of all HGS-OC cases [38,39], BRCA mutation carriers should be identified through a general screening program using next generation sequencing. Nevertheless, K. Claes indicated that bioinformatics and quality control metrics must be addressed in order to dispel the concern about great uncertainty caused by BRCA1/2 variants of unknown clinical significance and extract diagnostic value from whole-genome sequencing for hereditary cancers [40].

Regarding the association between BRCA1 and BRCA2 mutations and survival in women with EOC, a pooled analysis of 26 observational studies was reported to try to provide definitive evidence of the relative effect of germline BRCA1 and BRCA2 mutations on prognosis [41]. Despite the recent report of favorable outcome for BRCA2 mutation carriers compared with noncarriers [19], the results of many other relevant studies are not consistent, most of which had a weakness of small sample size less than 250 carriers, resulting in unreliable survival estimates [42-44]. In contrast, this study by Bolton et al. [41] included data from 1,213 EOC cases with pathogenic germline mutations in BRCA1 $(n=909)$ or BRCA2 $(n=304)$ and from 2,666 noncarriers. After adjusting for the year of study and diagnosis, BRCA1 ( $\mathrm{HR}, 0.78 ; 95 \% \mathrm{Cl}, 0.68$ to $0.89 ; \mathrm{p}<0.001)$ and BRCA2 (HR, 0.61; 95\% Cl, 0.50to 0.76; $\mathrm{p}<0.001$ ) mutation carriers showed a more favorable 5-year OS than noncarriers. This OS differences was still observed after additional adjustment for stage, grade, histology, and age at diagnosis. Thus, they concluded that a germline mutation in BRCA1 or BRCA2 was associated with improved 5-year OS, with that of BRCA2 carriers being the best.

Among other outstanding genomic studies in ovarian cancer published in 2012 was the study regarding somatic DICER1 mutations in nonepithelial ovarian cancers by HeraviMoussavi et al. [45]. DICER1 is an endoribonuclease in the RNase III family that is essential for processing miRNAs, which regulate translation and degradation of messenger RNA [46]. Although little is known about the pathogenesis of ovarian sex cord-stromal tumors because of their rare incidence, less than 3-5\% of ovarian cancers [47], germline mutation carriers of DICER1 are known to be at risk for these rare tumors [48]. In this study, however, somatic, rather than germline, DICER1 mutations were found in 29\% (30/102) of nonepithelial ovarian tumors, predominantly in Sertoli-Leydig cell tumors (26 of 43 , or $60 \%$ ). Based on the fact that these mutations change DICER1 function in specific cell types rather than obliterating it, they concluded that aberrant miRNA processing resulting from DICER1 hot-spot mutations might be a key oncogenic event in a certain type of nonepithelial ovarian cancers.

Last genetic study we review here is regarding the mutations in the p110 $\alpha$ subunit of phosphatidylinositol 3-kinase (PI3K), which is called PIK3CA [49]. PIK3CA mutations are known to be common in gynecologic and breast cancers ranged from $12 \%$ of ovarian cancer to $39 \%$ of endometrial cancer [50-52]. Based on the results of preclinical studies that suggested that PIK3CA mutations could predict response to PI3K/AKT/ the mammalian target of rapamycin (mTOR) inhibitors [53], Janku et al. [49] investigated PIK3CA mutation status of 140 patients with advanced breast $(n=29)$, cervical $(n=22)$, endometrial $(n=29)$, and ovarian $(n=60)$ cancers and found PIK3CA mutations in 25 patients (18\%). Of the 25 patients with PIK3CA mutations who experienced treatment failure with standard therapies, 23 were treated on a protocol that included a PI3K/ AKT/mTOR inhibitor and 7 (30\%) showed a partial response compared with a $10 \%$ response rate in patients with the same disease but wild-type PIK3CA treated on the same protocol $(p=0.04)$. They suggested that screening for PIK3CA mutations might support the use of PI3K/AKT/mTOR inhibitors in gynecologic and breast cancers.

\section{TREATMENT OF ADVANCED ENDOMETRIAL CANCER}

Given the limited responses of combination chemotherapy due to great toxicity and modest efficacy of hormonal agents in the treatment of recurrent or metastatic endometrial cancer $[54,55]$, there is a need to identify novel agents to improve survival outcomes of the patients with this intractable disease. In 2011, the NCIC clinical trials group reported promising results of a phase II study of temsirolimus, an mTOR inhibitor, in patients with advanced endometrial cancer [56]. Although they failed to demonstrate the correlation of molecular markers of PI3K/AKT/mTOR pathway such as p-mTOR, p-AKT, and $\mathrm{p}-\mathrm{S6}$, with the clinical outcomes, they showed encouraging single-agent activity, especially in chemotherapy-naive patients, $14 \%$ of partial response and $69 \%$ of stable disease. In line with these results, Fleming [57] gave a presentation regarding the future directions in management of advanced endometrial cancer at the 2012 IGCS meeting in Vancouver. She introduced two trials with some of the most successful targeted agents, for example, bevacizumab, metformin, and $\mathrm{PI3K/AKT/mTOR} \mathrm{inhibitor.} \mathrm{The} \mathrm{first} \mathrm{trial} \mathrm{was} \mathrm{a} \mathrm{phase} \mathrm{II} \mathrm{random-}$ ized study in which TC and bevacizumab was compared with TC and temsirolimus in advanced or recurrent endometrial cancer. After completion of patient recruitment, she hoped that promising results would be released sooner or later, 
considering the potential of increasing efficacy of targeted agents combined with conventional chemotherapy. Another study she mentioned during her speech was about GOG study of metformin in advanced endometrial cancer. Metformin is originally a well-tolerated, widely used, and inexpensive antidiabetic drug. It is not surprising, but still interesting, that metformin has been under investigation for its anti-cancer activities based on two main plausible benefits: decreasing tumor-stimulating insulin level and inhibiting mTOR pathway. Thus, GOG recently proposed a clinical trial of adding metformin to TC in advanced endometrial cancer because metformin is a non-toxic option.

Among the efforts to improve the prognosis of advanced endometrial cancer in 2012 was modification of schedule of adjuvant chemotherapy and pelvic radiation in uterine papillary serous carcinoma (UPSC). Although UPSC comprises less than $10 \%$ of endometrial cancers, it accounts for over $50 \%$ of all recurrences and disease-related deaths due to the frequent extra-pelvic recurrence and distant metastasis [58]. There is accumulating evidence that sequential use of TC followed by pelvic radiation can improve survival with acceptable toxicity in patients with advanced endometrial cancer including UPSC $[59,60]$. Furthermore, many studies on the optimal sequencing in adjuvant setting indicated that pelvic radiation "sandwiched" between combination chemotherapy might be a well-tolerated and efficacious regimen for patients with advanced or recurrent or high risk endometrial cancer $[59,61,62]$. Based on the hypothesis that the "sandwich" strategy allows for control of systemic disease with chemotherapy while treating micro-metastasis in the pelvis with radiation therapy (RT), Einstein et al. [63] confirmed the encouraging results of their pilot study [64]. Of a total of 81 UPSC patients who underwent complete tumor resection, 72 (89\%) completed the first 3 cycles of chemotherapy, paclitaxel $\left(175 \mathrm{mg} / \mathrm{m}^{2}\right)$ and carboplatin (AUC, 6.0 to 7.5) every 3 weeks, followed by RT and 65 (80\%) completed additional 3 cycles of chemotherapy after RT. Three-year \% survival probability for stage 1 and 2 patients was $84 \%$ and for stage 3 and 4 patients was $50 \%$. There were 11/435 chemotherapy cycles (2.5\%) grade 3-4 non-hematologic toxicities. Again, they concluded that RT "sandwiched" between TC is well-tolerated and highly efficacious in women with completely resected UPSC.

\section{TAILORED MANAGEMENT OF LOW-RISK ENDOMETRIAL CANCER}

The role of LND in the surgical management of low-risk endometrial cancer has long been a controversial issue
$[65,66]$. However, to complicate matters even more is the lack of consensus on the definition of low-risk disease [6770]. Traditionally, grade 1 and 2 endometrioid endometrial carcinoma (EEC) with myometrial invasion $\leq 50 \%$ has been considered low-risk [71]. With additional condition of primary tumor diameter $\leq 2 \mathrm{~cm}$, the prevalence of nodal metastasis in low-risk cases was shown to be $<1.0 \%$ and negative predictive value of these criteria was as high as $98.2 \%[72,73]$. Thus, according to these criteria, so called, "Mayo criteria", type I histology, grade 1 or 2 , myometrial invasion $\leq 50 \%$, primary tumor diameter $\leq 2 \mathrm{~cm}$, Dowdy et al. [74] have omitted LND in those patients identified as having low-risk disease since 1999, and reported the results of prospective assessment of survival, morbidity, and cost in this low-risk cohort. Among 1393 consecutive surgically managed cases, 385 (27.6\%) met the "Mayo criteria". LND was performed in 80 cases (20.8\%) of the study cohort and nodal metastasis was identified in only single case $(1.3 \%)$ of the 80 cases. The prevalence of $L N$ metastasis was $0.3 \%$ (1/385). The 5 -year cause-specific survival in LND and non-LND cases was $97.3 \%$ and $99.0 \%$, respectively $(p=0.32)$. However, complications in the first 30 days were significantly more common in the LND cohort than in nonLND cohort (37.5\% vs. $19.3 \% ; p<0.001)$. Thus, the authors concluded that LND increased morbidity without discernible benefits in low-risk EEC as defined by the "Mayo criteria" and hysterectomy with salpingo-oophorectomy alone, therefore, might be appropriate surgical management.

In addition to the "Mayo criteria," there are several models to predict patients at low-risk for LN metastasis. Kang et al. [75] assessed the predictive performance of LN metastasis of currently available 3 models: 1) a model modified from the GOG pilot study $[68,69]$; 2) one from the GOG-33 data [70]; and 3) one from Mayo clinic data [67], using the medical records of 947 patients with endometrial cancer who underwent surgery with LND. Criteria of model 1 are endometrium only of any grades, no myometrial invasion or invasion $\leq 50 \%$ of grade 1 and 2 or invasion $>50 \%$ of grade 1 , no lymphovascular space invasion/ no cervix or adnexa invasion, and endometrioid histology. Criteria of model 2 are no myometrial invasion of any grades or invasion $\leq 50 \%$ of grade 1 , no intraperitoneal disease, and endometrioid histology. The three models showed similar negative predictive values $(97.4 \%, 97.4 \%$, and $97.1 \%$, respectively), which indicated that the currently available prediction identifying the low-risk group of LN metastasis in endometrial cancer have a false negative rate about $2 \%$ at $10 \%$ of the assumed prevalence according to Bayes' theorem. They concluded that a false negative rate of $\leq 2 \%$ should be a criterion for determining clinical usefulness of pre- or intraoperative prediction models for low-risk of LN metastasis in 
the future.

Using this criterion of false negative rate of $\leq 2 \%$, the same group created and validated a preoperative risk prediction model for LN metastasis in endometrial cancer [76]. Among the data from a retrospective review of the medical records of 360 patients with endometrial cancer who underwent surgical staging, serum CA-125 levels and three magnetic resonance imaging (MRI) parameters (deep myometrial invasion, LN enlargement, and extension beyond uterine corpus) were found to be independent risk factors for LN metastasis through a multivariate logistic model. Using these 4 parameters as criteria for a low-risk group, 53\% of patients were defined as part of a low-risk group with predicted probability for $L N$ metastasis of $<4 \%$ and the false negative rate was $1.7 \%$. This model was externally validated in 180 patients from 2 independent institutions and showed good discrimination (area under the receiver operator characteristic curve, 0.85 ). Thus, they concluded that serum CA-125 and MRI findings can be used as good criteria for accurate identification of a lowrisk group for $L N$ metastasis in endometrial cancer.

Another driving force for tailored treatment of endometrial cancer is a minimally invasive surgery. After the first report of short-term advantages of laparoscopy regarding safety and length-of-stay endpoints versus open laparotomy in women with clinically early-stage endometrial cancer from LAP2 study [77], Walker et al. [78] of the GOG reported recurrence and survival outcomes of the LAP2 study. Recurrence rates at 3 years after surgery were $11.4 \%$ with laparoscopy and $10.2 \%$ with laparotomy (HR for laparoscopy, 1.14; $95 \% \mathrm{Cl}, 0.92$ to 1.46), which fell short of the predetermined threshold of 1.4 for noninferiority. Although the study seemed to be inconclusive, some reassurance could be provided because there was not a substantial increase in recurrence rates with laparoscopic surgery [79]. Furthermore, the LAP2 study did not raise potential several concerns about laparoscopic approaches such as port sites metastasis, facilitating seeding due to increased intraabdominal pressure with carbon dioxide, and tumor spillage of cancer during surgery. Berchuck et al. [79] said that the horse was already out of the barn in their editorial. To support their opinion, the dominant paradigm of minimally invasive surgery for endometrial cancer is now evolving toward robotic surgery. Although the Wright et al. [80] failed to demonstrate the comparative effectiveness of robotic hysterectomy versus laparoscopic hysterectomy for endometrial cancer in their population-based analysis, debate regarding the appropriate roles of laparoscopy and robotics in training programs and in practice is still ongoing and expected to incline in favor of minimally invasive surgery.

\section{EFFECTIVE MANAGEMENT OF CERVICAL CANCER AND VULVAR CANCER}

In 2005, Khan et al. [81] reported 10-year benefits of clinical HPV DNA testing for cervical pre-cancer and cancer risk prediction with a total of 20,810 women in the Kaiser Permanente health in Portland, USA, enrolled in a cohort study of HPV and cervical neoplasia. In 2012, the extended long-term follow-up results of the same cohort were published [82]. Of a total of 22,595 participating women, a final analytic cohort comprised 19,512 women (86.3\%) after exclusions. Of those, 4,098 women (18.1\%) had at least one screen 15 years or later after the cohort started. Women underwent follow-up prospectively with routine annual Papanicolaou (Pap) testing up to 18 years. The most important two clinical benefits of HPV test founded in this study were greater negative predictability and over-10-year cervical intraepithelial neoplasia (CIN)3+ predictability. A baseline negativity of HPV test was shown to reassure women against CIN3+ over the 18-year followup more accurately than a normal Pap (cumulative incidence rates, $0.90 \%$ vs. $1.27 \%$ ). Although both baseline Pap and HPV tests predicted $\mathrm{CIN} 3+$ within the first 2 years of follow-up, only HPV test predicted CIN3+ 10-18 years later $(p=0.004)$. Thus, they concluded that an HPV test might be used as the screen to rule out disease in healthy women, whereas Pap could be useful as a secondary diagnostic test to identify HPV-positive women at immediate risk of $\mathrm{CIN} 3+$ [82].

With regard to palliative chemotherapeutic regimens in stage IVB, persistent or recurrent cervical cancer, Kitagawa et al. [83] presented the results of JCOG study (JCOG 0505). They compared OS as a primary endpoint together with PFS, toxicities, and quality of life between TC vs. paclitaxel plus cisplatin (TP), the current standard regimen for stage IVB or recurrent cervical cancer. During the median follow-up of 17.4 months, median OS of TC and TP group was 17.5 versus 18.3 months (HR, 0.99; multiplicity adjusted $90 \% \mathrm{Cl}, 0.79$ to 1.25 ; noninferiority $\mathrm{p}=0.032$ ). TC group showed milder toxicity profiles than TP group except grade 3-4 thrombocytopenia and neuropathy. Proportion of non-hospitalization periods as a surrogate for quality of life was significantly higher in TC group than in TP group $(p<0.001)$. In conclusion, they recommended TC regimens as the new standard treatment for stage IVB or recurrent cervical cancer.

Regarding vulvar cancer, the results of two outstanding studies concerning LN related issues were reported in 2012. High rate of wound complication, predictable lymphatic drainage, and easy accessibility for dye injection make vulvar cancer an excellent target for the sentinel LN (SLN) concept [84]. Although many single institution-based studies showed the feasibility of SLN biopsy in patients with vulvar cancer 
[85-87], SLN biopsy is not established yet as an integral component of treatment of vulvar cancer like that in melanoma and breast cancer. Levenback et al. [84] reported the results of a prospective multicencer validation study (GOG 173), which was a phase III study of intraoperative lymphatic mapping in patients with invasive squamous cell carcinoma of the vulva. A total of 452 patients with squamous cell carcinoma with at least $1 \mathrm{~mm}$ invasion and $2 \mathrm{~cm} \leq$ tumor size $\leq 6 \mathrm{~cm}$, but without groin LNs suggestive of cancer was entered into the protocol and underwent intraoperative lymphatic mapping, SLN biopsy, and inguinal femoral LND. One hundred thirty three patients showed LN positivity, including 11 (8.3\%) with falsenegative LNs. Of note, however, $23 \%$ of true-positive patients were detected only by immunohistochemistry. The sensitivity was $91.7 \%$ (90\% lower confidence bound, $86.7 \%$ ) and false negative rate was 3.7\% (90\% upper confidence bound, 6.1\%), which was further decreased to $2.0 \%$ in women with tumor $<4 \mathrm{~cm}$. This suggests that women with primary tumors $<4 \mathrm{~cm}$ who met the eligibility criteria for this trial can be preoperatively counseled that if SLN is negative, the groin relapse risk due to a false-negative SLN would be less than 3\%. Accordingly, they concluded that SLN biopsy could be a reasonable alternative to inguinal LND in selected women with vulvar cancer. Further specific treatment recommendations may be available after the completion of the ongoing studies for SLN biopsy in vulvar cancer such as the Gronigen International Study on Sentinel Nodes in Vulvar Cancer (GROINSS VII).

Another large-scale study in vulvar cancer is the AGO CARE 1 study, which was presented at 2012 ASCO annual meeting [88]. This multicenter retrospective reviewed medical records of 1,637 patients, of which 491 (30.0\%) were groin node positive. Of 491, $240(48.9 \%)$ received adjuvant RT (85.8\%) or radiochemotherapy (14.2\%). Median OS was 43.4 months versus 212 months in LN positive and negative group, respectively, and increasing number of metastatic LNs was associated with shorter OS. Median OS of patients in adjuvant therapy group was significantly longer than that of patients who did not receive any adjuvant therapy irrespective of the number of affected LNs (66.9 months vs. 35.7 months; HR, 0.72; $95 \% \mathrm{Cl}, 0.53$ to $0.97 ; p=0.029)$. Thus, the authors concluded that unfavorable prognosis of vulvar cancer with metastatic LNs could be improved by adjuvant therapies no matter how many LNs were positive for malignancy.

\section{DEVELOPMENT OF IMAGE-BASED BRACHYTHERAPY IN CERVICAL CANCER}

Since the first report on the use of $\mathrm{CT}$ imaging in brachy- therapy about 25 years ago [89], image based brachytherapy in cervical cancer has been evolved from conventional 2 dimensional (2D) imaging-based planning to 3D MRI-based brachytherapy. Recently, recommendations for 3D insulated gate bipolar transistor (IGBT) were released by the Groupe Européen de Curiethérapie and the European Society for Therapeutic Radiology and Oncology (GEC-ESTRO) $[90,91]$, which use D90 and D100 for prescription instead of A point doses and include new concepts such as high-risk clinical target volume (HR CTV) and intermediate-risk CTV (IR CTV). Given the tumor regression after preceding external beam radiotherapy (EBRT) and chemotherapy and consequent change of the position of organs at risk (OAR), the repetitive imaging prior to each brachytherapy implant possibly allows for dose adaptation to the target, while sparing normal tissues at the same time [92].

In a questionnaire-based descriptive survey regarding the patterns of care for brachytherapy in Europe [93], the proportion of centers using CT-dosimetry increased from 33\% in 2002 to $61 \%$ of centers in 2007 . High-dose rate (HDR) brachytherapy was the most commonly reported technique, $65 \%$ of centers, while low-dose rate (LDR) and medium-dose rate (MDR) have declined. In another report from UK in 2011 [94], the proportion of centers offering image based brachytherapy has nearly trebled (71\%) since 2008 and MRI is being used by $20 \%$ for planning.

Supporting the trend of image based brachytherapy in cervical cancer, there is accumulating evidence that favor HDR brachytherapy vs. LDR in terms of an improvement in late toxicity [95], and CT-based 3D planning vs. conventional $2 \mathrm{D}$ imaging based planning with regard to conformity of target coverage and reduction of dose to OARs [96]. As more convincing evidence for 3D image based brachytherapy, a large non-randomized prospective study from France was published in 2012, which compared conventional 2D vs. $3 D$ dosimetry and confirmed that $3 \mathrm{D}$ brachytherapy is feasible and safe in routine practice [97]. In this study, three treatment regimens were defined: group 1 (mostly stage IB1): brachytherapy followed by surgery; 165 patients (2D arm, 76; 3D arm, 89); group 2 (mainly stage IB2-IIB): EBRT士 chemotherapy, brachytherapy, then surgery: 305 patients (2D arm, 142; 3D arm, 163); group 3 (mainly stage IIB-IIIB): EBRT \pm chemotherapy, then brachytherapy; 235 patients (2D arm, $118 ; 3 \mathrm{D}$ arm, 117). At 24 months, local relapse-free survival was $91.9 \%$ and $100 \%$ in group $1,84.7 \%$ and $93 \%$ in group 2, and $73.9 \%$ and $78.5 \%$ in group 3 for $2 \mathrm{D}$ and $3 \mathrm{D}$ arm, respectively ( $p=0.003$ ). Grade $3-4$ toxicity was $14.6 \%$ and $8.9 \%$ in group 1 , $12.5 \%$ and $8.8 \%$ in group 2 , and $22.7 \%$ and $2.6 \%$ in group 3 for $2 \mathrm{D}$ and $3 \mathrm{D}$ arm, respectively $(\mathrm{p}=0.002)$. Based on these results, 
they concluded that 3D brachytherapy has improved local control with half the toxicity observed with $2 \mathrm{D}$ dosimetry in cervical cancer treatment.

In terms of CT vs. MRI, MRI is generally accepted as the modality of choice despite the limited availability in the developing world [98]. A prospective study by Viswanathan et al. [99] showed that there was no difference between CT and MRI for OAR. However, CT significantly overestimated tumor width, resulting in significant difference in D90 (MRI, 8.7 vs. CT, 6.7; $p<0.01$ ) and D100 (MRI, 5.4 vs. CT, 3.7; $p<0.01$ ) for HR CTV. Thus, they concluded that MRI remained the standard for CTV definition. More recently, Potter et al. [100] reported clinical outcome of MRI-guided brachytherapy combined with 3D conformal radiotherapy in locally advanced cervical cancer. They showed an excellent overall local control of 95\% (98\% and $92 \%$ for tumors $2-5 \mathrm{~cm}$ and $>5 \mathrm{~cm}$, respectively) with low late toxicity (only $7.7 \%$ of grade $3-4$ events). They also reported a relative reduction of pelvic recurrence by $65-70 \%$ compared with historical Vienna series.

Promising results of the previous large scale prospective studies led to the multicenter prospective clinical trial, an International Study on MRI-Guided Brachytherapy in Locally Advanced Cervical Cancer (EMBRACE), which started in 2008 [92]. The results of EMBRACE study is expected to validate the GEC ESTRO recommendations in a multicenter setting through providing good local control rate as well as low morbidity.

\section{NEW PROMISING THERAPEUTIC STRATEGIES AGAINST HER2- OR HORMONE RECEPTOR-POSITIVE ADVANCED BREAST CANCER}

The anti-human epidermal growth factor receptor 2 (HER2) humanized monoclonal antibody trastuzumab and aromatase inhibitors such as letrozole and anastrozole are effective therapeutic approaches for patients with HER2-positive metastatic and postmenopausal hormone-receptor (HR)positive advanced breast cancer, respectively. Nevertheless, most patients with advanced and metastatic breast cancer eventually experience disease progression, highlighting the need for new targeted therapies for advanced disease [101]. Regarding this issue, positive results of three outstanding phase III randomized clinical trials of were published in 2012: CLEOPATRA, EMILIA, and BOLERO-2.

The Clinical Evaluation of Pertuzumab and Trastuzumab (CLEOPATRA) study assessed the efficacy and safety of pertuzumab plus trastuzumab plus docetaxel (pertuzumab group), as compared with placebo plus trastuzumab plus docetaxel (control group), as first-line treatment for patients with HER2positive metastatic breast cancer [102]. Pertuzumab, another
anti-HER2 humanized monoclonal antibody, binds HER2 at a different epitope of the HER2 extracellular domain from that at which trastuzumab binds, inhibiting not only homodimerization of HER2 but also heterodimerization of HER1/HER2 and HER2/HER3 [103]. Thus, Pertuzumab, given together with trastuzumab, was shown to provide a more comprehensive blockade of HER2 signaling and greater antitumor activity than either agent alone in HER2-positive tumor models [104,105]. In CLEOPATRA study, a total of 808 patients with HER2-positive metastatic breast cancer were randomized to pertuzumab or control group. After a loading dose of trastuzumab (8 mg/ $\mathrm{kg}$ ) and pertuzumab $840 \mathrm{mg}$ (or placebo in control group), patients received a maintenance dose of trastuzumab $(6 \mathrm{mg} /$ $\mathrm{kg}$ ) and pertuzumab or placebo $(420 \mathrm{mg})$ every 3 weeks until disease progression or the development of toxic effects that could not be effectively managed, respectively. At least six cycles of docetaxel was recommended every 3 weeks with 75 $\mathrm{mg} / \mathrm{m}^{2}$. The median progression-free survival was $12.4 \mathrm{vs} .18 .5$ months in the control and pertuzumab group, respectively ( $\mathrm{HR}, 0.62 ; 95 \% \mathrm{Cl}, 0.51$ to $0.75 \mathrm{l} ; \mathrm{p}<0.001)$. The interim OS analysis showed a strong trend in favor of pertuzumab group. They concluded that the combination of pertuzumab plus trastuzumab plus docetaxel, as compared with placebo plus trastuzumab plus docetaxel, significantly increased PFS with no increase in cardiac toxic effects.

The EMILIA study assessed the efficacy and safety of trastuzumab emtansine (T-DM1) in patients with HER2positive advanced breast cancer previously treated with trastuzumab and a taxane [106]. T-DM1 is an antibody-drug conjugate incorporating HER2-targeted antitumor properties of trastuzumab with the cytotoxic activity of the microtubuleinhibitory agent DM-1, which allows intracellular drug delivery specifically to HER2-overexpressing cells, thereby improving the therapeutic index and minimizing exposure of normal tissue. In EMILIA study, a total of 991 patients with HER2-positive advanced breast cancer previously treated with trastuzumab and a taxane were randomly assigned to T-DM1 or lapatinib plus capecitabine, a current standard option for disease progression with trastuzumab. The median PFS was 9.6 versus 6.4 months with T-DM1 and lapatinib plus capecitabine, respectively ( $\mathrm{HR}, 0.65 ; 95 \% \mathrm{Cl}, 0.55$ to $0.77 ; \mathrm{p}<0.001)$. The median OS at the second interim analysis crossed the stopping boundary for efficacy (30.9 vs. 25.1 months; HR, 0.68; 95\% Cl, 0.55 to 0.85; $\mathrm{p}<0.001$ ). In addition, grade 3 or 4 adverse events occurred more frequently in lapatinib plus capecitabine than in T-DM1 (57\% vs. $41 \%$ ). Thus, they concluded that T-DM1 significantly prolonged PFS and OS with less toxicity than lapatinib plus capecitabine in patients with HER2-positive advanced breast cancer previously treated with trastuzumab and a taxane. 
The Breast Cancer Trials of Oral Everolimus-2 (BOLERO-2) study evaluated the efficacy and safety of the combination of everolimus and exemestane in patients with HR-positive breast cancer refractory to non-steroidal aromatase inhibitors [107]. Even though hormone therapy has the pivotal role in the treatment of HR-positive advanced breast cancer, endocrine resistance is often observed either primarily or secondarily. Among the mechanisms of action of endocrine resistance in breast cancer is the activation of MTOR signaling pathway, which is responsible for ligand-independent estrogen receptor activation $[108,109]$. Based on the promising results of preclinical and clinical phase II study of everolimus, an mTOR inhibitor, combined with aromatase inhibitors $[110,111]$, BOLERO-2 study randomly assigned 724 patients with HR-positive, endocrine resistant advanced breast cancer to everolimus plus exemestane or exemestane plus placebo group in a 2:1 ratio. The interim analysis at the point of 359 PFS events showed that median PFS was 10.6 and 4.1 months in everolimus plus exemestane and placebo plus exemestane group, respectively, according to central assessment ( $\mathrm{HR}, 0.36$; $95 \% \mathrm{Cl}, 0.27$ to $0.47 ; \mathrm{p}<0.001)$. Most common three grade 3 or 4 adverse events were stomatitis ( $8 \%$ vs. $1 \%$ ), anemia ( $6 \%$ vs. $<1 \%$ ), and dyspnea (4\% vs. $1 \%$ ) in everolimus plus exemestane versus placebo plus exemestane group, respectively. They concluded that everolimus plus exemestane, an aromatase inhibitor, improved PFS in patients with HR-positive advanced breast cancer previously treated with nonsteroidal aromatase inhibitors.

\section{UPDATES OF MAJOR PRACTICE GUIDELINES IN GYNECOLOGIC ONCOLOGY}

As of December, 2012, we will briefly review the latest version of the National Comprehensive Cancer Network (NCCN) guidelines in cervical, ovarian, uterine cancers [112], the American Cancer Society (ACS) guideline regarding screening for the early detection of cervical precancerous lesions and cancer [113], and guideline summary National Guideline Clearinghouse (NGC)-8958 regarding the management of gynecologic issues in women with breast cancer [114].

The updates to version 2.2012 of the NCCN cervical cancer screening guidelines mainly include four parts. First, the footnote indicates regarding the onset of screening, "cervical cancer screening should begin at age 21 years. Screening before age 21 should be avoided, because it may lead to unnecessary and harmful evaluation and treatment in women at very low risk of cancer." Second, the screening guidelines for early detection of cervical cancer were updated based on Saslow et al. [113], which will be covered later. Third, regarding high-risk HPV testing, several points were updated: 1) HPV DNA specific test for 16 or $16 / 18$ genotype was recommended as a category 1 first testing option for the follow-up. 2) The follow-up for "both tests negative or high-risk HPV test negative and cytology positive for ASC-of undetermined significance (ASCUS)" was modified as "resume routine screening per guidelines." 3) "Use of high-risk HPV DNA testing alone is not recommended for screening in any age group. Cotesting is not recommended for screening in women age 21-29 years." Fourth, regarding adenocarcinoma in situ (AIS), followup and management was added and "AIS or microinvasion" was added to coloposcopic biopsy finding with follow-up management.

The updates in version 2.2013 of the NCCN guidelines for cervical cancer include 3 items. First, smoking cessation and counseling intervention was added to workup. Second, a new section for fertility sparing treatment options for stages $1 \mathrm{~A}$ and 1B1 was added. Third, regarding the surveillance, followup schedules were provided specifically with time intervals and tests to be done for detecting recurrence.

The updates in version 1.2013 of the guidelines for ovarian cancer were as follows. For workup, "PET/CT scan may be indicated for indeterminate lesions if results will alter management." was added. The finding of "stage 1A or 1B, grade 3" was modified to include "or clear cell" and "clear-cell pathology is grade 3." was removed. For secondary adjuvant therapy in stage II, III, and IV diseases after complete clinical remission, clinical trial was moved to be the first option. For primary treatment of borderline EOC after incomplete surgical staging, "observation is a reasonable option regardless of whether fertility is desired." and "For pathologically proven low malignant potential, LN evaluation may be considered on a case-by-case basis." were added. Appendectomy was added in procedures that may be considered for optimal surgical cytoreduction. Under cytotoxic therapy, carboplatin/ gemcitabine/bevacizumab was added to preferred regimen option as a category $2 \mathrm{~B}$ recommendation for patients who have not previously received bevacizumab. And a new page for "surveillance for germ cell and sex cord-stromal tumors" was added.

The updates in version 3.2012 of the NCCN guidelines for uterine neoplasms were as follows. Optional initial evaluation of genetic counseling/testing was revised to "Consider genetic counseling/testing for young patients ( $<55$ years) and those with a significant family history of endometrial and/ or colorectal cancer." In relatives with Lynch syndrome, but without endometrial cancer, a yearly endometrial biopsy is recommended until a hysterectomy and bilateral salpingo- 
oophorectomy are performed. For stage IB, grade 3 with adverse risk factors, the recommendation was revised as "pelvic RT and/or vaginal brachytherapy \pm chemotherapy (category 2B for chemotherapy) or observe (category 2B)." For primary treatment of medically inoperable endometrial carcinoma, "Consider hormone therapy in select patients" was added as an option with corresponding footnote, "Patients should be closely monitored. Consider endometrial biopsies every 3-6 months." For papillary serous or clear cell carcinoma or carcinosarcoma, "CA-125 (optional) and MRI/CT as clinically indicated" was added for additional workup and "Most carcinosarcoma are treated the same as poorly differentiated adenocarcinomas." was added. For uterine sarcoma, the recommendation in stage II, III, "consider chemotherapy" changed from category $2 \mathrm{~B}$ to $2 \mathrm{~A}$ and temozolomide was added to other single agent options.

An update to the ACS guideline regarding screening for the early detection of cervical precancerous lesions and cancer is announced based on a systematic evidence review, contribution from 6 working groups, and a recent symposium cosponsored by the ACS, the American Society for Colposcopy and Cervical Pathology (ASCCP), and the American Society for Clinical Pathology (ASCP). The new screening recommendations provide screening strategies according to age including the use of cytology and HPV testing, the age at which to begin and exit screening, and follow-up of women after screening according to the results. Considering the balance between benefits and harms associated with high cost of colposcopy in USA, screening every 3-5 years is recommended. However, physicians should follow the guidelines with modification according to the relative incidence of cervical cancer and medical cost of his or her country.

Lastly, NGC of US Department of Health and Human Services released guideline summary titled "Management gynecologic issues in women with breast cancer" to review the effect of breast cancer treatment on common women's health issues such as fertility, contraceptive management, menopause, sexual function, and osteoporosis and to provide a rationale for follow-up and treatment of these gynecologic issues. As a major recommendation with good and consistent scientific evidence (level A), selective serotonin reuptake inhibitors (SSRIs) and serotonin-norepinephrine reuptake inhibitors (SNRIs) have both been shown to be safe and to reduce the severity of hot flushes in patients with breast cancer, although caution must be used when using these agents in conjunction with tamoxifen. Gabapentin and clonidine are other options for management of hot flushes. The following 5 recommendations are based on limited or inconsistent scientific evidence (level B). The 2009 NCCN Task Force report recommends that pharmacologic therapy should be considered for women with breast cancer who have T scores between -1.5 and -2.0. Routine endometrial biopsy and uterine ultrasonography are not recommended for postmenopausal women taking tamoxifen without bleeding. Contraceptive options for patients with breast cancer include barrier methods, such as condoms and diaphragms, the copper intrauterine device, and sterilization. Pregnancy after breast cancer is not thought to increase breast cancer recurrence. If future pregnancy is desired for women in whom breast cancer has been diagnosed, appropriate consultation with fertility specialists should be offered to ascertain whether immediate assisted reproductive strategies are possible to preserve fertility. As a level C recommendation which is based primarily on consensus and expert opinion, nonhormonal methods should be considered firstline treatment for vaginal atrophy in women with a history of hormone-sensitive breast cancer.

\section{CONCLUSION}

Although the level of survival improvement did not meet our expectations, bevacizumab showed some potential efficacy both in the first-line and salvage treatment of EOC. Based on these results, a number of trials with various designs are ongoing for different populations. Moreover, there is a movement to study the effect of continuing bevacizumab beyond progression. Apart from bevacizumab, many molecular targeted agents are in a queue for winning clinical trials. Unfortunately however, no sensational and relevant result is available so far, but slow and steady wins the fight. This is one of the reasons why we have kept following the results of related studies in this reviews. From the review of this year, updates of major clinical guidelines will be covered at the last part of the review. We hope that many influential study results which were addressed in the previous issues could appear as recommendations in those clinical guidelines in the near future.

\section{CONFLICT OF INTEREST}

No potential conflict of interest relevant to this article was reported.

\section{REFERENCES}

1. Burger RA, Brady MF, Bookman MA, Fleming GF, Monk 
BJ, Huang $H$, et al. Incorporation of bevacizumab in the primary treatment of ovarian cancer. N Engl J Med 2011;365:2473-83.

2. Perren TJ, Swart AM, Pfisterer J, Ledermann JA, PujadeLauraine $\mathrm{E}$, Kristensen $\mathrm{G}$, et al. A phase 3 trial of bevacizumab in ovarian cancer. N Engl J Med 2011;365:2484-96.

3. Aghajanian C, Blank SV, Goff BA, Judson PL, Teneriello MG, Husain A, et al. OCEANS: a randomized, doubleblind, placebo-controlled phase III trial of chemotherapy with or without bevacizumab in patients with platinumsensitive recurrent epithelial ovarian, primary peritoneal, or fallopian tube cancer. J Clin Oncol 2012;30:2039-45.

4. Aghajanian C, Blank SV, Goff BA, Judson PL, Nycum LR, Sovak MA, et al. An updated safety analysis of OCEANS, a randomized, double-blind, phase III trial of gemcitabine $(G)$ and carboplatin (C) with bevacizumab (BV) or placebo $(\mathrm{PL})$ followed by $\mathrm{BV}$ or $\mathrm{PL}$ to disease progression (PD) in patients with platinum-sensitive (Plat-S) recurrent ovarian cancer. J Clin Oncol 2012;30:abstr 5054.

5. Pujade-Lauraine E, Hilpert F, Weber B, Reuss A, Poveda A, Kristensen $\mathrm{G}$, et al. AURELIA: a randomized phase III trial evaluating bevacizumab (BEV) plus chemotherapy (CT) for platinum (PT)-resistant recurrent ovarian cancer (OC). J Clin Oncol 2012;30:abstr LBA 5002.

6. Kristensen G, Berton-Rigaud D, Hilpert F, Reuss A, Bover I, Raspagliesi F, et al. The effect of bevaxizumab (BEV) plus chemotherapy (CT) for platinum-resistant ovarian cancer (OC) with ascites: analysis of the AURELIA trial. Int J Gynecol Cancer 2012;22(8 suppl 3):E103.

7. Katsumata N, Yasuda M, Takahashi F, Isonishi S, Jobo T, Aoki D, et al. Dose-dense paclitaxel once a week in combination with carboplatin every 3 weeks for advanced ovarian cancer: a phase 3, open-label, randomised controlled trial. Lancet 2009;374:1331-8.

8. Gonzalez-Martin A, Gladieff L, Tholander B, Stroyakovsky D, Gore ME, Segalla JGM, et al. Safety of front-line bevacizumab (BEV) combined with weekly paclitaxel (WPAC) and q3w carboplatin (C) for ovarian cancer (OC): Results from OCTAVIA. J Clin Oncol 2012;30:abstr 5017.

9. Arnold D, Andre T, Bennouna J, Sastre J, Osterlund PJ, Greil R, et al. Bevacizumab (BEV) plus chemotherapy (CT) continued beyond first progression in patients with metastatic colorectal cancer (mCRC) previously treated with BEV plus CT: results of a randomized phase III intergroup study (TML study). J Clin Oncol 2012;30:abstr CRA 3503.

10. Previs R, Perry L, Sperling J, Brevis K, McCann G, Moore K, et al. Bevacizumab beyond progression is not associated with prolonged progression-free survival in epithelial ovarian cancer. Int J Gynecol Cancer 2012;22(8 suppl 3): E220.

11. Patel AG, Sarkaria JN, Kaufmann SH. Nonhomologous end joining drives poly(ADP-ribose) polymerase (PARP) inhibitor lethality in homologous recombinationdeficient cells. Proc Natl Acad Sci U S A 2011;108:340611.

12. Konstantinopoulos PA, Cannistra SA. Comparing poly (ADP-ribose) polymerase inhibitors with standard chemotherapy in BRCA-mutated, recurrent ovarian cancer: lessons learned from a negative trial. J Clin Oncol 2012;30:347-50.

13. Miles DW, Chan A, Dirix LY, Cortes J, Pivot X, Tomczak $P$, et al. Phase III study of bevacizumab plus docetaxel compared with placebo plus docetaxel for the first-line treatment of human epidermal growth factor receptor 2-negative metastatic breast cancer. J Clin Oncol 2010; 28:3239-47.

14. Rottenberg S, Jaspers JE, Kersbergen A, van der Burg E, Nygren AO, Zander SA, et al. High sensitivity of BRCA1deficient mammary tumors to the PARP inhibitor AZD2281 alone and in combination with platinum drugs. Proc Natl Acad Sci U S A 2008;105:17079-84.

15. Kaye SB, Lubinski J, Matulonis U, Ang JE, Gourley C, Karlan BY, et al. Phase II, open-label, randomized, multicenter study comparing the efficacy and safety of olaparib, a poly (ADP-ribose) polymerase inhibitor, and pegylated liposomal doxorubicin in patients with BRCA1 or BRCA2 mutations and recurrent ovarian cancer. J Clin Oncol 2012;30:372-9.

16. Audeh MW, Carmichael J, Penson RT, Friedlander M, Powell B, Bell-McGuinn KM, et al. Oral poly(ADP-ribose) polymerase inhibitor olaparib in patients with BRCA1 or BRCA2 mutations and recurrent ovarian cancer: a proofof-concept trial. Lancet 2010;376:245-51.

17. Fong PC, Yap TA, Boss DS, Carden CP, Mergui-Roelvink M, Gourley $C$, et al. Poly(ADP)-ribose polymerase inhibition: frequent durable responses in BRCA carrier ovarian cancer correlating with platinum-free interval. J Clin Oncol 2010;28:2512-9.

18. Gordon AN, Fleagle JT, Guthrie D, Parkin DE, Gore ME, Lacave AJ. Recurrent epithelial ovarian carcinoma: a randomized phase III study of pegylated liposomal doxorubicin versus topotecan. J Clin Oncol 2001;19:3312-22.

19. Yang D, Khan S, Sun Y, Hess K, Shmulevich I, Sood AK, et al. Association of BRCA1 and BRCA2 mutations with survival, chemotherapy sensitivity, and gene mutator phenotype in patients with ovarian cancer. JAMA 2011;306:1557-65. 
20. Sakai W, Swisher EM, Karlan BY, Agarwal MK, Higgins J, Friedman C, et al. Secondary mutations as a mechanism of cisplatin resistance in BRCA2-mutated cancers. Nature 2008;451:1116-20.

21. Ledermann J, Harter P, Gourley C, Friedlander M, Vergote I, Rustin $G$, et al. Olaparib maintenance therapy in platinum-sensitive relapsed ovarian cancer. N Engl J Med 2012;366:1382-92.

22. Vergote IB, Joly F, Katsaros D, Coens C, Reinthaller A, Hall $M$, et al. Randomized phase III study of erlotinib versus observation in patients with no evidence of disease progression after first-line platin-based chemotherapy for ovarian carcinoma: a GCIG and EORTC-GCG study. J Clin Oncol 2012;30:abstr LBA 5000.

23. Colombo N, Kutarska E, Dimopoulos M, Bae DS, RzepkaGorska I, Bidzinski M, et al. Randomized, open-label, phase III study comparing patupilone (EPO906) with pegylated liposomal doxorubicin in platinum-refractory or -resistant patients with recurrent epithelial ovarian, primary fallopian tube, or primary peritoneal cancer. J Clin Oncol 2012;30:3841-7.

24. Kowalski RJ, Giannakakou P, Hamel E. Activities of the microtubule-stabilizing agents epothilones $A$ and $B$ with purified tubulin and in cells resistant to paclitaxel (Taxol(R)). J Biol Chem 1997;272:2534-41.

25. Altmann KH, Wartmann M, O'Reilly T. Epothilones and related structures: a new class of microtubule inhibitors with potent in vivo antitumor activity. Biochim Biophys Acta 2000;1470:M79-91.

26. Ten Bokkel Huinink WW, Sufliarsky J, Smit WM, Spanik S, Wagnerova M, Hirte HW, et al. Safety and efficacy of patupilone in patients with advanced ovarian, primary fallopian, or primary peritoneal cancer: a phase I, openlabel, dose-escalation study. J Clin Oncol 2009;27:3097103.

27. Zhang L, Yang N, Park JW, Katsaros D, Fracchioli S, Cao G, et al. Tumor-derived vascular endothelial growth factor up-regulates angiopoietin-2 in host endothelium and destabilizes host vasculature, supporting angiogenesis in ovarian cancer. Cancer Res 2003;63:3403-12.

28. Cannistra SA, Matulonis UA, Penson RT, Hambleton J, Dupont J, Mackey H, et al. Phase II study of bevacizumab in patients with platinum-resistant ovarian cancer or peritoneal serous cancer. J Clin Oncol 2007;25:5180-6.

29. Herbst RS, Hong D, Chap L, Kurzrock R, Jackson E, Silverman JM, et al. Safety, pharmacokinetics, and antitumor activity of AMG 386, a selective angiopoietin inhibitor, in adult patients with advanced solid tumors. J Clin Oncol 2009;27:3557-65.
30. Mita AC, Takimoto CH, Mita M, Tolcher A, Sankhala K, Sarantopoulos J, et al. Phase 1 study of AMG 386, a selective angiopoietin 1/2-neutralizing peptibody, in combination with chemotherapy in adults with advanced solid tumors. Clin Cancer Res 2010;16:3044-56.

31. Karlan BY, Oza AM, Richardson GE, Provencher DM, Hansen VL, Buck M, et al. Randomized, double-blind, placebo-controlled phase II study of AMG 386 combined with weekly paclitaxel in patients with recurrent ovarian cancer. J Clin Oncol 2012;30:362-71.

32. Mahner S. Phase III HECTOR study: recurring platinum sensitive ovarian cancer [Internet]. Cancer Intelligence; 2012 [cited 2012 Nov 25]. Available from: http://ecancer. org/tv/conference/157/1688.

33. Koensgen D, Stengel D, Belau A, Klare P, Oskay-Oezcelik G, Steck T, et al. Topotecan and carboplatin in patients with platinum-sensitive recurrent ovarian cancer: results of a multicenter NOGGO: phase I/II study. Cancer Chemother Pharmacol 2008;62:393-400.

34. Rose PG, Monk BJ, Provencher D, Hartney J, Legenne P, Lane S. An open-label, single-arm phase II study of intravenous weekly (days 1 and 8) topotecan in combination with carboplatin (day 1 ) every 21 days as secondline therapy in patients with platinum-sensitive relapsed ovarian cancer. Gynecol Oncol 2011;120:38-42.

35. Katsumata N, Yasuda M, Isonishi S, Michimae H, Kimura E, Aoki D, et al. Long-term follow-up of a rancomized trial comparing conventional paclitaxel and carboplatin with dose-dense weekly paclitaxel and carboplatin in women with advanced epithelial ovarian, fallopian tube, or primary peritoneal cancer: JGOG 3016 trial. J Clin Oncol 2012;30:abstr 5003.

36. Kim K, Ryu SY. Major clinical research advances in gynecologic cancer 2009. J Gynecol Oncol 2009;20:2039.

37. Cancer Genome Atlas Research Network. Integrated genomic analyses of ovarian carcinoma. Nature 2011; 474:609-15.

38. Levy-Lahad E. Is it necessary to screen everybody for inherited cancer? when, why and how. Ann Oncol 2012; 23(suppl 9):ix34.

39. Suh DH, Kim K, Kim JW. Major clinical research advances in gynecologic cancer in 2011. J Gynecol Oncol 2012;23: 53-64.

40. Claes K. Challenges of dealing with next generation sequencing for hereditary cancer in clinical practice. Ann Oncol 2012;23(suppl 9):ix33.

41. Bolton KL, Chenevix-Trench G, Goh C, Sadetzki S, Ramus SJ, Karlan BY, et al. Association between BRCA1 and 
BRCA2 mutations and survival in women with invasive epithelial ovarian cancer. JAMA 2012;307:382-90.

42. Chetrit A, Hirsh-Yechezkel G, Ben-David Y, Lubin F, Friedman E, Sadetzki S. Effect of BRCA1/2 mutations on long-term survival of patients with invasive ovarian cancer: the national Israeli study of ovarian cancer. J Clin Oncol 2008;26:20-5.

43. Cass I, Baldwin RL, Varkey T, Moslehi R, Narod SA, Karlan BY. Improved survival in women with BRCA-associated ovarian carcinoma. Cancer 2003;97:2187-95.

44. Buller RE, Shahin MS, Geisler JP, Zogg M, De Young BR, Davis CS. Failure of BRCA1 dysfunction to alter ovarian cancer survival. Clin Cancer Res 2002;8:1196-202.

45. Heravi-Moussavi A, Anglesio MS, Cheng SW, Senz J, Yang W, Prentice L, et al. Recurrent somatic DICER1 mutations in nonepithelial ovarian cancers. N Engl J Med 2012;366:234-42.

46. Bartel DP. MicroRNAs: genomics, biogenesis, mechanism, and function. Cell 2004;116:281-97.

47. Colombo N, Peiretti M, Castiglione M. Non-epithelial ovarian cancer: ESMO clinical recommendations for diagnosis, treatment and follow-up. Ann Oncol 2009;20 Suppl 4:24-6.

48. Bahubeshi A, Tischkowitz M, Foulkes WD. miRNA processing and human cancer: DICER1 cuts the mustard. Sci Transl Med 2011;3:111ps46.

49. Janku F, Wheler JJ, Westin SN, Moulder SL, Naing A, Tsimberidou AM, et al. PI3K/AKT/mTOR inhibitors in patients with breast and gynecologic malignancies harboring PIK3CA mutations. J Clin Oncol 2012;30:77782.

50. Levine DA, Bogomolniy F, Yee CJ, Lash A, Barakat RR, Borgen PI, et al. Frequent mutation of the PIK3CA gene in ovarian and breast cancers. Clin Cancer Res 2005;11: 2875-8.

51. Miyake T, Yoshino K, Enomoto T, Takata T, Ugaki H, Kim $A$, et al. PIK3CA gene mutations and amplifications in uterine cancers, identified by methods that avoid confounding by PIK3CA pseudogene sequences. Cancer Lett 2008;261:120-6.

52. Hayes MP, Wang $H$, Espinal-Witter R, Douglas W, Solomon GJ, Baker SJ, et al. PIK3CA and PTEN mutations in uterine endometrioid carcinoma and complex atypical hyperplasia. Clin Cancer Res 2006;12:5932-5.

53. Di Nicolantonio F, Arena S, Tabernero J, Grosso S, Molinari F, Macarulla $T$, et al. Deregulation of the PI3K and KRAS signaling pathways in human cancer cells determines their response to everolimus. J Clin Invest 2010;120:2858-66.
54. Emons G, Heyl W. Hormonal treatment of endometrial cancer. J Cancer Res Clin Oncol 2000;126:619-23.

55. Humber CE, Tierney JF, Symonds RP, Collingwood M, Kirwan J, Williams C, et al. Chemotherapy for advanced, recurrent or metastatic endometrial cancer: a systematic review of Cochrane collaboration. Ann Oncol 2007;18:409-20.

56. Oza AM, Elit L, Tsao MS, Kamel-Reid S, Biagi J, Provencher DM, et al. Phase II study of temsirolimus in women with recurrent or metastatic endometrial cancer: a trial of the NCIC Clinical Trials Group. J Clin Oncol 2011;29:3278-85.

57. Fleming G. New therapies to treat advanced endometrial cancer [Internet]. Cancer Intelligence; 2012 [cited 2012 Nov 25]. Available from: http://ecancer.org/tv/ pubdate/1676.

58. Togami S, Sasajima Y, Oi T, Ishikawa M, Onda T, Ikeda $S$, et al. Clinicopathological and prognostic impact of human epidermal growth factor receptor type 2 (HER2) and hormone receptor expression in uterine papillary serous carcinoma. Cancer Sci 2012;103:926-32.

59. Lupe K, D'Souza DP, Kwon JS, Radwan JS, Harle IA, Hammond JA, et al. Adjuvant carboplatin and paclitaxel chemotherapy interposed with involved field radiation for advanced endometrial cancer. Gynecol Oncol 2009;114:94-8.

60. Obermair A, Mileshkin L, Bolz K, Kondalsamy-Chennakesavan S, Cheuk R, Vasey P, et al. Prospective, non-randomized phase 2 clinical trial of carboplatin plus paclitaxel with sequential radical pelvic radiotherapy for uterine papillary serous carcinoma. Gynecol Oncol 2011;120:179-84.

61. Geller MA, Ivy J, Dusenbery KE, Ghebre R, Isaksson Vogel $\mathrm{R}$, Argenta PA. A single institution experience using sequential multi-modality adjuvant chemotherapy and radiation in the "sandwich" method for high risk endometrial carcinoma. Gynecol Oncol 2010;118:19-23.

62. Geller MA, Ivy JJ, Ghebre R, Downs LS Jr, Judson PL, Carson LF, et al. A phase II trial of carboplatin and docetaxel followed by radiotherapy given in a "Sandwich" method for stage III, IV, and recurrent endometrial cancer. Gynecol Oncol 2011;121:112-7.

63. Einstein MH, Frimer M, Kuo DY, Reimers LL, Mehta K, Mutyala $S$, et al. Phase II trial of adjuvant pelvic radiation "sandwiched" between combination paclitaxel and carboplatin in women with uterine papillary serous carcinoma. Gynecol Oncol 2012;124:21-5.

64. Fields AL, Einstein MH, Novetsky AP, Gebb J, Goldberg GL. Pilot phase II trial of radiation "sandwiched" between combination paclitaxel/platinum chemotherapy in patients with uterine papillary serous carcinoma (UPSC). 
Gynecol Oncol 2008;108:201-6.

65. Benedetti Panici P, Basile S, Maneschi F, Alberto Lissoni A, Signorelli M, Scambia G, et al. Systematic pelvic lymphadenectomy vs. no lymphadenectomy in earlystage endometrial carcinoma: randomized clinical trial. J Natl Cancer Inst 2008;100:1707-16.

66. Kitchener H, Swart AM, Qian Q, Amos C, Parmar MK. Efficacy of systematic pelvic lymphadenectomy in endometrial cancer (MRC ASTEC trial): a randomised study. Lancet 2009:373:125-36.

67. Mariani A, Dowdy SC, Cliby WA, Gostout BS, Jones MB, Wilson TO, et al. Prospective assessment of lymphatic dissemination in endometrial cancer: a paradigm shift in surgical staging. Gynecol Oncol 2008;109:11-8.

68. Boronow RC. Surgical staging of endometrial cancer: evolution, evaluation, and responsible challenge--a personal perspective. Gynecol Oncol 1997;66:179-89.

69. Boronow RC, Morrow CP, Creasman WT, Disaia PJ, Silverberg SG, Miller A, et al. Surgical staging in endometrial cancer: clinical-pathologic findings of a prospective study. Obstet Gynecol 1984;63:825-32.

70. Creasman WT, Morrow CP, Bundy BN, Homesley HD, Graham JE, Heller PB. Surgical pathologic spread patterns of endometrial cancer: a Gynecologic Oncology Group Study. Cancer 1987;60:2035-41.

71. Morrow CP, Bundy BN, Kurman RJ, Creasman WT, Heller P, Homesley HD, et al. Relationship between surgicalpathological risk factors and outcome in clinical stage I and II carcinoma of the endometrium: a Gynecologic Oncology Group study. Gynecol Oncol 1991;40:55-65.

72. Milan M, Java J, Walker J, Parker L, Metzinger D, Coleman R. Incidence of nodal metastasis in endometrioid endometrial cancer risk groups: a Gynecologic Oncology Groups multicenter review. Gynecol Oncol 2011;120 (Suppl 1):S4.

73. Convery PA, Cantrell LA, Di Santo N, Broadwater G, Modesitt SC, Secord AA, et al. Retrospective review of an intraoperative algorithm to predict lymph node metastasis in low-grade endometrial adenocarcinoma. Gynecol Oncol 2011;123:65-70.

74. Dowdy SC, Borah BJ, Bakkum-Gamez JN, Weaver AL, McGree ME, Haas LR, et al. Prospective assessment of survival, morbidity, and cost associated with lymphadenectomy in low-risk endometrial cancer. Gynecol Oncol 2012;127:5-10.

75. Kang S, Lee JM, Lee JK, Kim JW, Cho CH, Kim SM, et al. How low is low enough? Evaluation of various riskassessment models for lymph node metastasis in endometrial cancer: a Korean multicenter study. J Gynecol
Oncol 2012;23:251-6.

76. Kang S, Kang WD, Chung HH, Jeong DH, Seo SS, Lee $J M$, et al. Preoperative identification of a low-risk group for lymph node metastasis in endometrial cancer: a Korean gynecologic oncology group study. J Clin Oncol 2012;30:1329-34.

77. Walker JL, Piedmonte MR, Spirtos NM, Eisenkop SM, Schlaerth JB, Mannel RS, et al. Laparoscopy compared with laparotomy for comprehensive surgical staging of uterine cancer: Gynecologic Oncology Group Study LAP2. J Clin Oncol 2009;27:5331-6.

78. Walker JL, Piedmonte MR, Spirtos NM, Eisenkop SM, Schlaerth JB, Mannel RS, et al. Recurrence and survival after random assignment to laparoscopy versus laparotomy for comprehensive surgical staging of uterine cancer: Gynecologic Oncology Group LAP2 Study. J Clin Oncol 2012;30:695-700.

79. Berchuck A, Secord AA, Havrilesky LJ. Minimally invasive surgery for endometrial cancer: the horse is already out of the barn. J Clin Oncol 2012;30:681-2.

80. Wright JD, Burke WM, Wilde ET, Lewin SN, Charles AS, $\mathrm{Kim} \mathrm{JH}$, et al. Comparative effectiveness of robotic versus laparoscopic hysterectomy for endometrial cancer. J Clin Oncol 2012;30:783-91.

81. Khan MJ, Castle PE, Lorincz AT, Wacholder S, Sherman $M$, Scott DR, et al. The elevated 10-year risk of cervical precancer and cancer in women with human papillomavirus (HPV) type 16 or 18 and the possible utility of type-specific HPV testing in clinical practice. J Natl Cancer Inst 2005;97:1072-9.

82. Castle PE, Glass AG, Rush BB, Scott DR, Wentzensen N, Gage JC, et al. Clinical human papillomavirus detection forecasts cervical cancer risk in women over 18 years of follow-up. J Clin Oncol 2012;30:3044-50.

83. Kitagawa R, Katsumata N, Shibata T, Nakanishi T, Nishimura S, Ushijima K, et al. A randomized, phase III trial of paclitaxel plus carboplatin (TC) versus paclitaxel plus cisplatin (TP) in stage IVb, persistent or recurrent cervical cancer: Japan Clinical Oncology Group study (JCOG 0505). J Clin Oncol 2012;30:abstr 5006.

84. Levenback CF, Ali S, Coleman RL, Gold MA, Fowler JM, Judson PL, et al. Lymphatic mapping and sentinel lymph node biopsy in women with squamous cell carcinoma of the vulva: a gynecologic oncology group study. J Clin Oncol 2012;30:3786-91.

85. Levenback C, Coleman RL, Burke TW, Bodurka-Bevers D, Wolf JK, Gershenson DM. Intraoperative lymphatic mapping and sentinel node identification with blue dye in patients with vulvar cancer. Gynecol Oncol 
2001;83:276-81.

86. Rob L, Robova H, Pluta M, Strnad P, Kacirek J, Skapa P, et al. Further data on sentinel lymph node mapping in vulvar cancer by blue dye and radiocolloid Tc99. Int J Gynecol Cancer 2007;17:147-53.

87. de Hullu JA, Hollema H, Piers DA, Verheijen RH, van Diest PJ, Mourits MJ, et al. Sentinel lymph node procedure is highly accurate in squamous cell carcinoma of the vulva. J Clin Oncol 2000;18:2811-6.

88. Mahner S, Jueckstock JK, Hilpert F, Lubbe D, Harter P, Gregorio ND, et al. Impact of adjuvant therapy in lymphnode positive vulvar cancer: the AGO CARE 1 study. J Clin Oncol 2012;30:abstr 5007.

89. Ling CC, Schell MC, Working KR, Jentzsch K, Harisiadis $\mathrm{L}$, Carabell $\mathrm{S}$, et al. CT-assisted assessment of bladder and rectum dose in gynecological implants. Int J Radiat Oncol Biol Phys 1987;13:1577-82.

90. Haie-Meder C, Potter R, Van Limbergen E, Briot E, De Brabandere M, Dimopoulos J, et al. Recommendations from Gynaecological (GYN) GEC-ESTRO Working Group (I): concepts and terms in 3D image based 3D treatment planning in cervix cancer brachytherapy with emphasis on MRI assessment of GTV and CTV. Radiother Oncol 2005;74:235-45.

91. Potter R, Haie-Meder C, Van Limbergen E, Barillot I, De Brabandere M, Dimopoulos J, et al. Recommendations from gynaecological (GYN) GEC ESTRO working group (II): concepts and terms in 3D image-based treatment planning in cervix cancer brachytherapy-3D dose volume parameters and aspects of 3D image-based anatomy, radiation physics, radiobiology. Radiother Oncol 2006;78:67-77.

92. Potter R, Fidarova E, Kirisits C, Dimopoulos J. Imageguided adaptive brachytherapy for cervix carcinoma. Clin Oncol (R Coll Radiol) 2008;20:426-32.

93. Guedea F, Venselaar J, Hoskin P, Hellebust TP, Peiffert D, Londres $B$, et al. Patterns of care for brachytherapy in Europe: updated results. Radiother Oncol 2010;97:51420.

94. Tan LT. Implementation of image-guided brachytherapy for cervix cancer in the UK: progress update. Clin Oncol (R Coll Radiol) 2011;23:681-4.

95. Narayan K, van Dyk S, Bernshaw D, Rajasooriyar C, Kondalsamy-Chennakesavan S. Comparative study of LDR (Manchester system) and HDR image-guided conformal brachytherapy of cervical cancer: patterns of failure, late complications, and survival. Int J Radiat Oncol Biol Phys 2009;74:1529-35.

96. Shin KH, Kim TH, Cho JK, Kim JY, Park SY, Kim DY, et al.
CT-guided intracavitary radiotherapy for cervical cancer: Comparison of conventional point A plan with clinical target volume-based three-dimensional plan using dose-volume parameters. Int J Radiat Oncol Biol Phys 2006;64:197-204.

97. Charra-Brunaud C, Harter V, Delannes M, Haie-Meder C, Quetin P, Kerr C, et al. Impact of 3D image-based PDR brachytherapy on outcome of patients treated for cervix carcinoma in France: results of the French STIC prospective study. Radiother Oncol 2012;103:305-13.

98. Sadozye AH, Reed N. A review of recent developments in image-guided radiation therapy in cervix cancer. Curr Oncol Rep 2012;14:519-26.

99. Viswanathan AN, Dimopoulos J, Kirisits C, Berger D, Potter R. Computed tomography versus magnetic resonance imaging-based contouring in cervical cancer brachytherapy: results of a prospective trial and preliminary guidelines for standardized contours. Int J Radiat Oncol Biol Phys 2007;68:491-8.

100. Potter R, Georg P, Dimopoulos JC, Grimm M, Berger D, Nesvacil N, et al. Clinical outcome of protocol based image (MRI) guided adaptive brachytherapy combined with 3D conformal radiotherapy with or without chemotherapy in patients with locally advanced cervical cancer. Radiother Oncol 2011;100:116-23.

101. Nahta R, Esteva FJ. Trastuzumab: triumphs and tribulations. Oncogene 2007;26:3637-43.

102. Baselga J, Cortes J, Kim SB, Im SA, Hegg R, Im YH, et al. Pertuzumab plus trastuzumab plus docetaxel for metastatic breast cancer. N Engl J Med 2012;366:109-19.

103. Baselga J, Swain SM. Novel anticancer targets: revisiting ERBB2 and discovering ERBB3. Nat Rev Cancer 2009;9: 463-75.

104. Franklin MC, Carey KD, Vajdos FF, Leahy DJ, de Vos AM, Sliwkowski MX. Insights into ErbB signaling from the structure of the ErbB2-pertuzumab complex. Cancer Cell 2004;5:317-28.

105. Scheuer W, Friess T, Burtscher H, Bossenmaier B, Endl J, Hasmann M. Strongly enhanced antitumor activity of trastuzumab and pertuzumab combination treatment on HER2-positive human xenograft tumor models. Cancer Res 2009;69:9330-6.

106. Verma S, Miles D, Gianni L, Krop IE, Welslau M, Baselga J, et al. Trastuzumab emtansine for HER2-positive advanced breast cancer. N Engl J Med 2012;367:1783-91.

107. Baselga J, Campone M, Piccart M, Burris HA 3rd, Rugo $H S$, Sahmoud T, et al. Everolimus in postmenopausal hormone-receptor-positive advanced breast cancer. $\mathrm{N}$ Engl J Med 2012;366:520-9. 
108. Johnston SR. Clinical efforts to combine endocrine agents with targeted therapies against epidermal growth factor receptor/human epidermal growth factor receptor 2 and mammalian target of rapamycin in breast cancer. Clin Cancer Res 2006;12:1061s-1068s.

109. Yamnik RL, Digilova A, Davis DC, Brodt ZN, Murphy CJ, Holz MK. S6 kinase 1 regulates estrogen receptor alpha in control of breast cancer cell proliferation. J Biol Chem 2009;284:6361-9.

110. Boulay A, Rudloff J, Ye J, Zumstein-Mecker S, O'Reilly T, Evans DB, et al. Dual inhibition of mTOR and estrogen receptor signaling in vitro induces cell death in models of breast cancer. Clin Cancer Res 2005;11:5319-28.

111. Baselga J, Semiglazov V, van Dam P, Manikhas A, Bellet M, Mayordomo J, et al. Phase II randomized study of neoadjuvant everolimus plus letrozole compared with placebo plus letrozole in patients with estrogen receptor-positive breast cancer. J Clin Oncol 2009;27: 2630-7.
112. National Comprehensive Cancer Network. NCCN clinical practice guidelines in oncology [Internet]. Fort Washington, PA: National Comprehensive Cancer Network; 2012 [cited 2012 Dec 25]. Available from: http:// www.nccn.org/professionals/physician_gls/f_guidelines. asp.

113. Saslow D, Solomon D, Lawson HW, Killackey M, Kulasingam SL, Cain J, et al. American Cancer Society, American Society for Colposcopy and Cervical Pathology, and American Society for Clinical Pathology screening guidelines for the prevention and early detection of cervical cancer. CA Cancer J Clin 2012;62:147-72.

114. American College of Obstetricians and Gynecologists (ACOG). Management of gynecologic issues in women with breast cancer [Internet]. Washington, DC: ACOG; 2012 [cited 2012 Dec 25]. Available from: http://www. guideline.gov/content.aspx?id=36055\&search=gynecol ogic+issues+in+women+with+breast+cancer. 